\title{
MODELING A CFD DOMAIN FOR THEFT DETECTION OF OIL DERIVATIVES IN PIPELINES
}

\author{
Sidney Santos Doriaa, André Telles da Cunha Lima \\ a SENAI CIMATEC, Brazil
}

\begin{abstract}
This work presents a computational modelling of the conditions of oil derivatives theft in pipelines and simulate the related physical phenomena looking for an approach to detect and track such loss. We compare velocity data probed from two simulated pipelines, one pipeline intact and another one with a drilled outlet. We apply the Fourier Transform in the velocity data to get the main frequency of fluctuations. The two main results are: (i) the power curve of the main frequencies in the intact pipeline can be described by a Power Law and (ii) the main frequencies area very low, below $1 \mathrm{~Hz}$.
\end{abstract}

Keywords: Computational Fluid Dynamics; OpenFOAM; Computer Simulations; Oil Derivatives Theft; Fourier Transform.

\section{MODELANDO UM DOMÍNIO CFD PARA DETECÇÃO DE ROUBO DE DERIVADOS DE PETRÓLEO EM DUTOS DE TRANSMISSÃO}

Resumo: Este trabalho apresenta uma modelagem computacional das condições de roubo de derivados de petróleo em dutos de transmissão para simulação de fenômenos físicos, criando condições de abordagem para detectar perdas nesses dutos. Comparam-se dados de velocidade obtidos de sondagem em dois dutos simulados, sendo um intacto e outro perfurado para roubo. Aplica-se então a Transformada de Fourier, obtendo-se as frequências majoritárias dentre as flutuações de velocidade do fluido. Os resultados principais são: (i) a curva de potência das frequências no duto intacto é descritível através de uma Lei de Potência e (ii) as frequências majoritárias são muito baixas, abaixo de $1 \mathrm{~Hz}$.

Palavras-chave: Dinâmica de Fluidos Computacional; OpenFOAM; Simulações Computacionais; Roubo de Derivados de Petróleo; Transformada de Fourier. 


\section{INTRODUCTION}

Methods for leak detection with various applicability and restrictions have been proposed to prevent further loss and environmental damage. Hence, taking the proper method (e.g., acoustic monitoring, optical monitoring, flow balance monitoring) for a scenario is possible to detect a fluid leak in a pipeline with reasonable accuracy. Pipelines of water, oil and derivatives have been further investigated because of the environmental risks and costs involved. In sense of model a regular leak, previous works have adopted a classic representation of a small fracture, typically designed as a small hole with a diameter of $0.1 \%$ to $1 \%$ of the pipe diameter to study cases $[1,2]$, mostly by physical approach.

Brazil is facing recurrent thefts of refined oil derivatives (e.g., fuel gas, gasoline) in distribution pipelines in such a way which the related phenomena is quite different from a classic small leak. Thieves are drilling outlets in those pipes with precision, using drill bits of $10 \mathrm{~mm}$ to $20 \mathrm{~mm}$, due to its wide availability and low cost in local market. Finally, a valve is attached to the outlet to drain the product in favorable hours, as shown in Figure 1. So, it is convenient to develop a new approach to detect and track such leaks.

Figure 1. A Fuel Theft Scenario in Brazil [3].

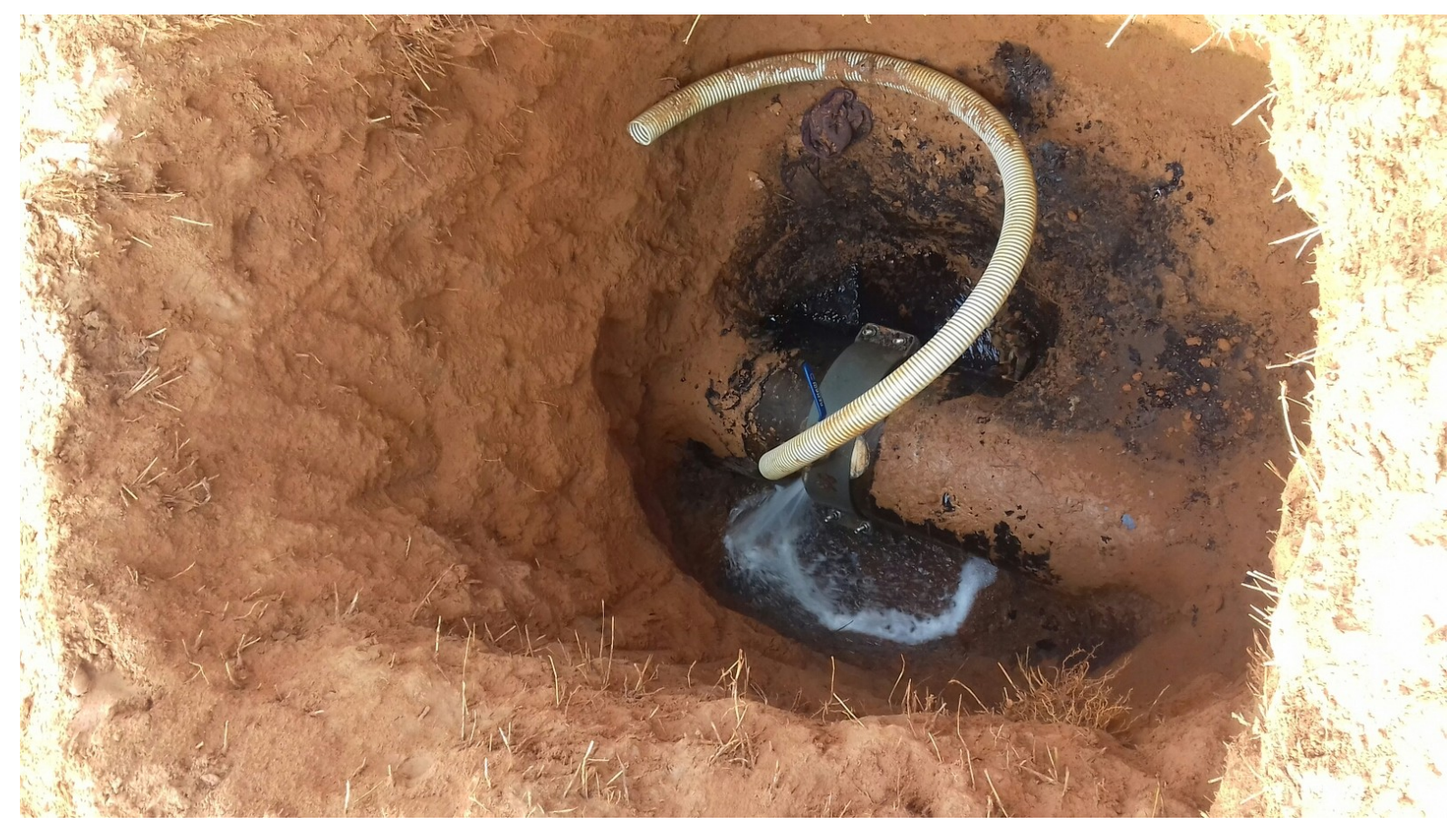

Considering that a physical approach might require some costly arrangements in an exploratory endeavor, several numerical algorithms are available for the different terms in the Navier-Stokes equations and a set of turbulence models exists, we employ computational fluid dynamics (CFD) to predict flow characteristics in a pipeline domain to study related phenomena and develop a new approach to detect and track oil derivatives theft. 


\section{METHODOLOGY}

\subsection{Numerical Calculations}

We use OpenFOAM[4] version 7 to solve the following continuity (1) and NavierStokes (2) equations:

$$
\begin{gathered}
\frac{\partial}{\partial t} \rho+\nabla \cdot(\rho \boldsymbol{u})=0 \\
\rho \frac{D u}{D t}=-\nabla p+\mu \nabla^{2} \mathbf{u}+\mathbf{F}
\end{gathered}
$$

where $\rho\left(\mathrm{kg}^{\mathrm{m}} \mathrm{m}^{-3}\right)$ is the fluid density, $p$ is the fluid pressure, $\boldsymbol{u}\left(\mathrm{m} . \mathrm{s}^{-1}\right)$ is the fluid velocity vector, $\mu\left(\mathrm{kg} \cdot \mathrm{m}^{-1} . \mathrm{s}^{-1}\right)$ is the total dynamic viscosity and $\boldsymbol{F}$ is the set of external forces, per unit volume. The numerical schemes are defined as follows.

We define a three-dimensional finite volume domain as a pipe $\Pi$ of length $L=$ $10 \mathrm{~m}$ along the $x$ axis and of diameter $D=0.1 \mathrm{~m}$ in the section plan along the $y$ and the $z$ axes. We assume that $D$ is constant along of $\Pi$ and there is an isothermic condition. Figure 2 illustrates $\Pi$. We model $\Pi$ as a Computer Aided Design (CAD) which is then converted with SnappyHexMesh ${ }^{1}$ as orthogonal, unstructured grid, based on hexahedral cells. We perform a sensitivity analysis for grid resolution and discretization scheme using grids of (i) $0.5 \mathrm{M}$ cells; (ii) $1.2 \mathrm{M}$ cells and (iii) $4.4 \mathrm{M}$ cells, finding that grid resolution (i) presents no declining in accuracy and is the optimum choice to simulate $\Pi$. We apply a non-slip boundary condition to the $\Pi$ walls. Also, we apply zero gradient pressure boundary condition to the inlet and to the outlet.

Figure 2. 3D Finite-Volume Domain П.

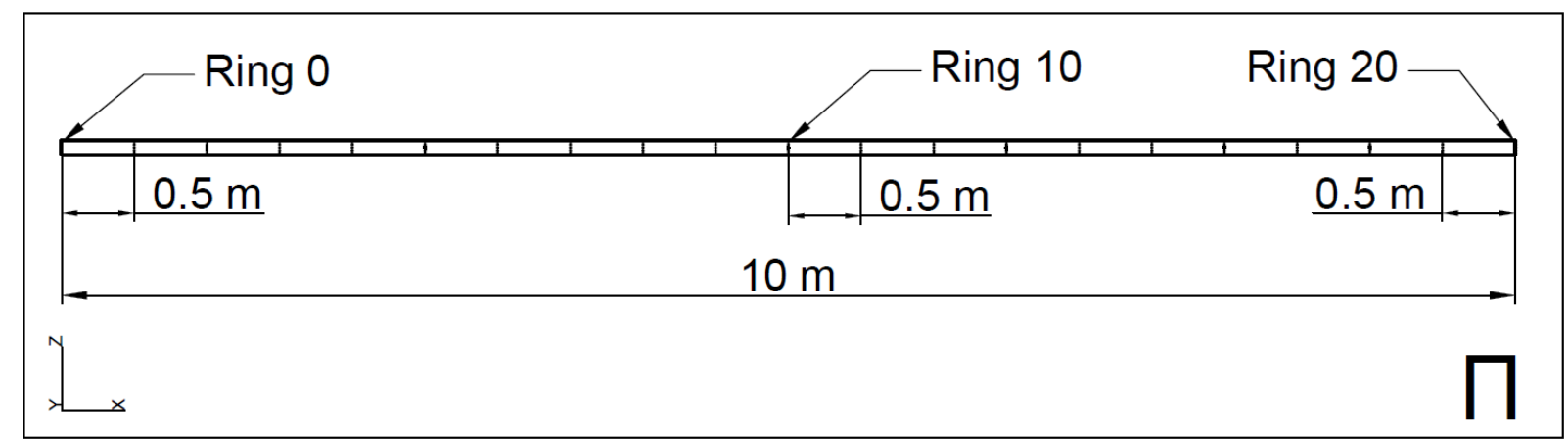

To collect comprehensive data of the physical phenomena we configure probing in OpenFOAM, placing sets of nine probes forming symmetric radial stars inscribed in circles named rings. Rings are placed at every $0.5 \mathrm{~m}$ along the $x$ axis of $\Pi$ as shown in Figure 3. Figure 4 details how probes are placed in an example ring of $\Pi$.

\footnotetext{
${ }^{1}$ An OpenFOAM' mesh generation utility.
} 
Figure 3. Rings Along $\Pi$.

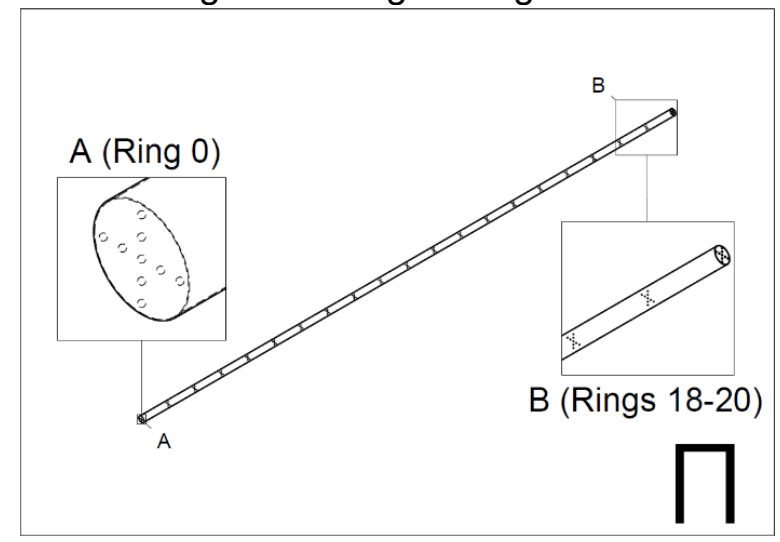

Figure 4. Ring 0 in Detail.

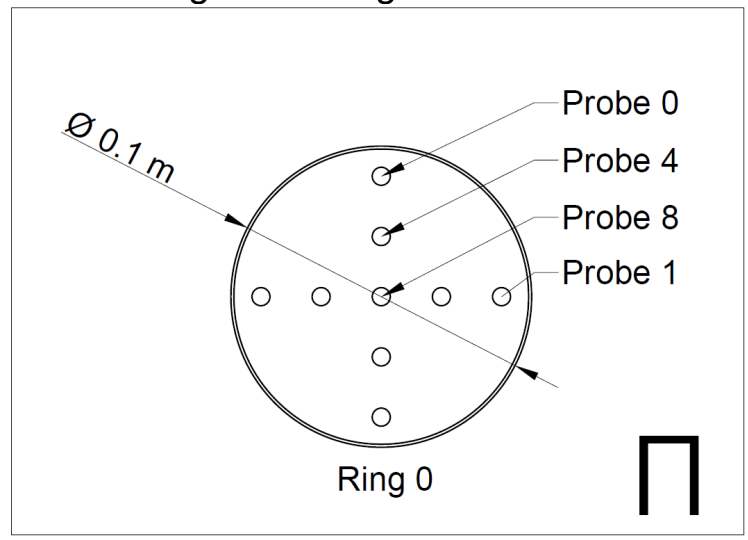

We adjust the fluid parameters as an incompressible fuel oil with $\rho=800 \mathrm{~kg} \cdot \mathrm{m}^{-3}$ and $\mu=0.01 \mathrm{~kg} \cdot \mathrm{m}^{-1} \cdot \mathrm{s}^{-1}$. We define the fluid velocity vector $\vec{U}\left(U_{x}, U_{y}, U_{z}\right)$ at the inlet as a constant average value $\left(v_{x}, v_{y}, v_{z}\right)=\left(v_{0}, 0,0\right)$, to push the fluid in movement from the inlet to the outlet. To explore the impact of $v_{0}$ on the phenomena, we consider four different values: (i) $v_{0}=0.5 \mathrm{~m} / \mathrm{s}, v_{0}=1.0 \mathrm{~m} / \mathrm{s}, v_{0}=3.0 \mathrm{~m} / \mathrm{s}$ and $v_{0}=5.0 \mathrm{~m} / \mathrm{s}$. Considering the fluid parameters, the $v_{0}$ values in $\Pi$ result approximately and respectively into Reynolds numbers $(R e)[5]$ : (i) $R e=4.0 \times 10^{3}, R e=2.4 \times 10^{4}$ and $R e=$ $4.0 \times 10^{4}$.

Once that those Reynolds numbers define a laminar to turbulent regime, pisoFoam is the adopted solver, with turbulence model defined as Large Eddy Simulation (LES)[6], improved by dynamic one-equation model (dynamicKEqn)[7] for the sub-grid scale.

Starting at time $t=0$, the solutions for the Equations (1) and (2) are obtained for 400,000 values of time, with $\Delta T=5 \times 10^{-5} S$, considering the necessary interval to discipline the Courant number. Total time (endTime) of the simulation is $20 \mathrm{~s}$.

\subsection{Power Spectra Analysis}

To detect leaks in $\Pi$ we calculate the power spectral density (PSD) of velocity fluctuations probed, focusing on the flow stream longitudinal direction ( $x$ axis) component of the fluid velocity vector $\vec{U}$ (i.e., $U_{x}$ ). The power spectral density of the turbulence at a given location $\boldsymbol{r}$ is denoted by

$$
P(\boldsymbol{r}, \omega)=u(\boldsymbol{r}, \omega) * u(\boldsymbol{r}, \omega)
$$


where $u(\boldsymbol{r}, \omega)$ is the Fourier transform of the $x$ component of the velocity fluctuation at position $r$, corresponding to $\omega=2 \pi f$, with $f$ representing the frequency In Equation (3)

$$
u(\boldsymbol{r}, \omega=2 \pi f)=\int_{-\infty}^{+\infty} u_{i}(\boldsymbol{r}, t) e^{2 \pi i f t} d t
$$

If the velocities are given at $N$ discrete values of time, with time interval $\Delta t$, the discrete Fourier transform is calculated at frequencies $f_{n}=n / N \Delta$ :

$$
u_{n}\left(\boldsymbol{r}, f_{n}\right) \equiv \sum_{k=0}^{N-1} u\left(\boldsymbol{r}, t_{k}\right) e^{2 \pi i k n / N}
$$

In terms of the discrete Fourier transform, the power spectral density becomes:

$$
P\left(\boldsymbol{r}, \omega=2 \pi f_{n}\right)=\Delta^{2}\left|u_{n}(\boldsymbol{r})\right|^{2}
$$
integral

The power of the fluctuation at a position $\boldsymbol{r}$ inside a frequency interval $F$ is the

$$
\Delta P(\boldsymbol{r})=\int_{F} P(\boldsymbol{r}, f) d f \approx \Delta^{2} \sum_{f_{n} \in F}\left|u_{n}(\boldsymbol{r})\right|^{2}
$$

\section{RESULTS AND DISCUSSION}

We present the results of the simulations of $\Pi$ in two conditions: (a) with the pipeline in pristine condition, with no leak, and (b) with the pipeline in the MadMax condition, with a leak. We also compare both conditions varying initial fluid velocity $\left(v_{0}\right)$. Figure 5 presents both conditions with $v_{0}=1.0 \mathrm{~m} / \mathrm{s}$. Figure 6 presents both conditions with $v_{0}=3.0 \mathrm{~m} / \mathrm{s}$ and Figure 7 presents both conditions with $v_{0}=5.0 \mathrm{~m} / \mathrm{s}$.

Note that in all scenarios the predominant frequency (i.e., with maximum power) of $U_{x}$ fluctuations is a very low frequency, lower than $1 \mathrm{~Hz}$. Hence, the results are presented showing frequencies up to $2.5 \mathrm{~Hz}$ to improve details in visualization. Images at left are from the Pristine Pipeline and images at right are from the MadMax Pipeline. 
Figure 5. Power Spectral Density of $\Pi(1 \mathrm{~m} / \mathrm{s})$
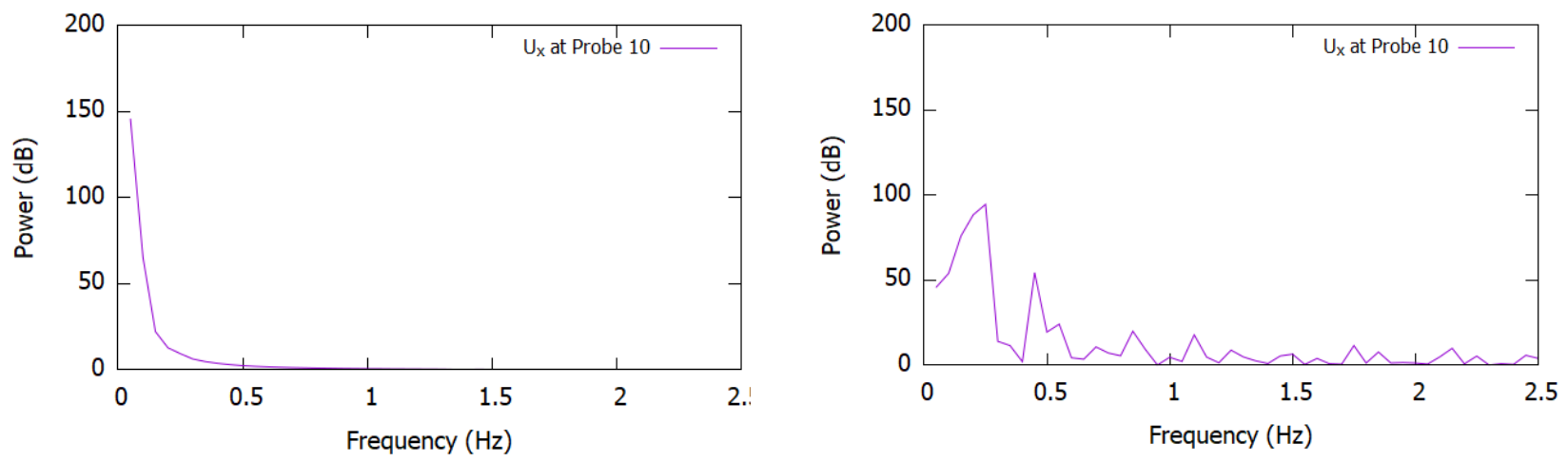

Figure 6. Power Spectral Density of $\Pi(3 \mathrm{~m} / \mathrm{s})$
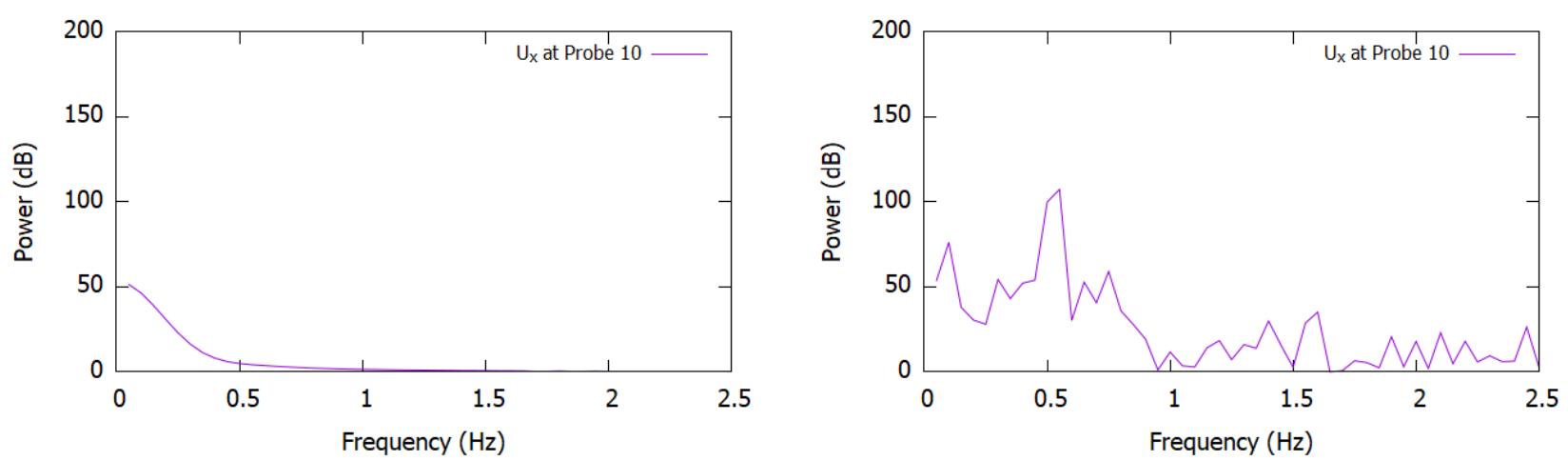

Figure 7. Power Spectral Density of $\Pi(5 \mathrm{~m} / \mathrm{s})$
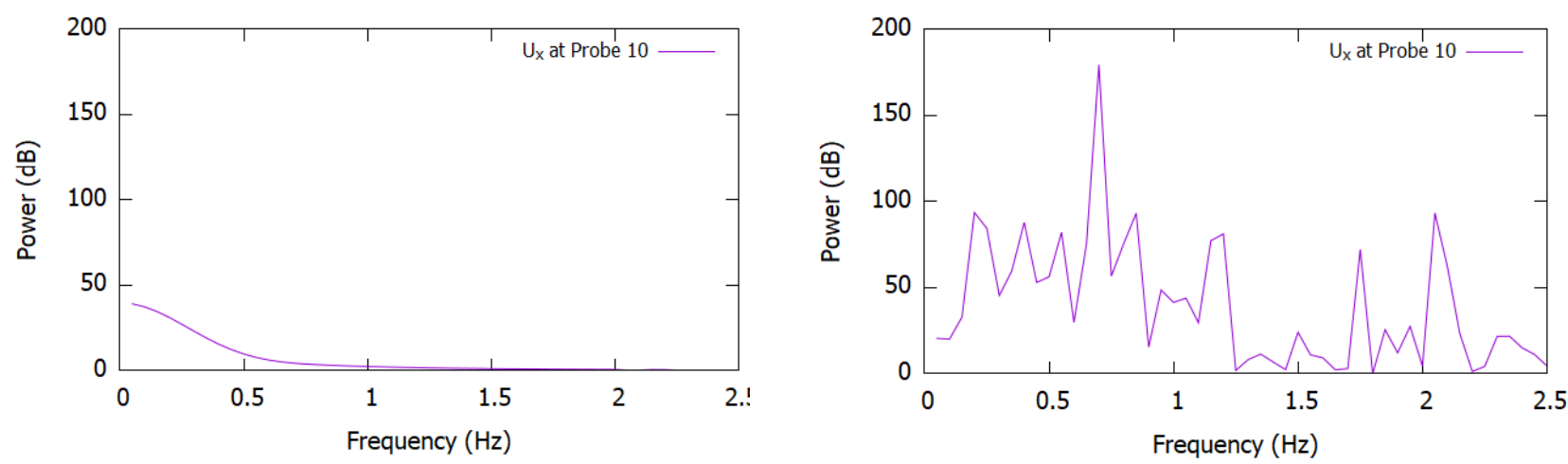

In a first inspection of the graphics it is possible to note:

- A peculiar power spectral density for pristine scenarios and for MadMax scenarios, independently of the $v_{0}$

- A regular, well-formed decaying of power in pristine scenarios

- A spread power spectral density, with many frequencies with great power

- An increase in predominant frequency as $v_{0}$ increases

We further investigate the decaying of frequency power in pristine scenarios. We use regression looking for functions that govern those scenarios starting from the idea that the fitting curves are similar to Power Laws in the form $f(x)=a \cdot x^{b}$. 
Figure 8 presents the curve that fits pristine scenario at $v_{0}=1.0 \mathrm{~m} / \mathrm{s}$. Figure 9 presents the curve that fits pristine scenario at $v_{0}=3.0 \mathrm{~m} / \mathrm{s}$. Figure 10 presents the curve that fits pristine scenario at $v_{0}=5.0 \mathrm{~m} / \mathrm{s}$. Note that in MadMax scenarios fitting curves have a weak correlation $\left(R^{2}\right)$, but in Pristine scenarios the fitting correlations are strong, independently of $v_{0}$. This might suggest that pipelines without leaks have govern functions of power spectral density. This might suggest a path to investigate if these functions could be predictable on pipeline dimensions.

Figure 8. Power Spectral Density of $\Pi$ with Fitting Curve $(1 \mathrm{~m} / \mathrm{s})$
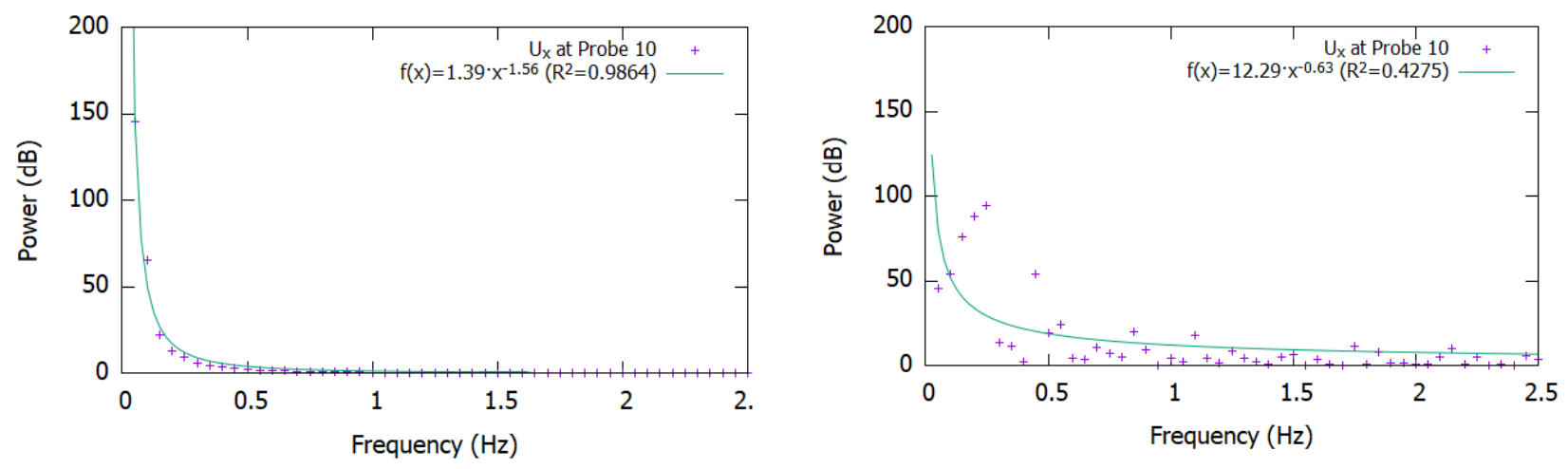

Figure 9. Power Spectral Density of $\Pi$ with Fitting Curve $(3 \mathrm{~m} / \mathrm{s})$
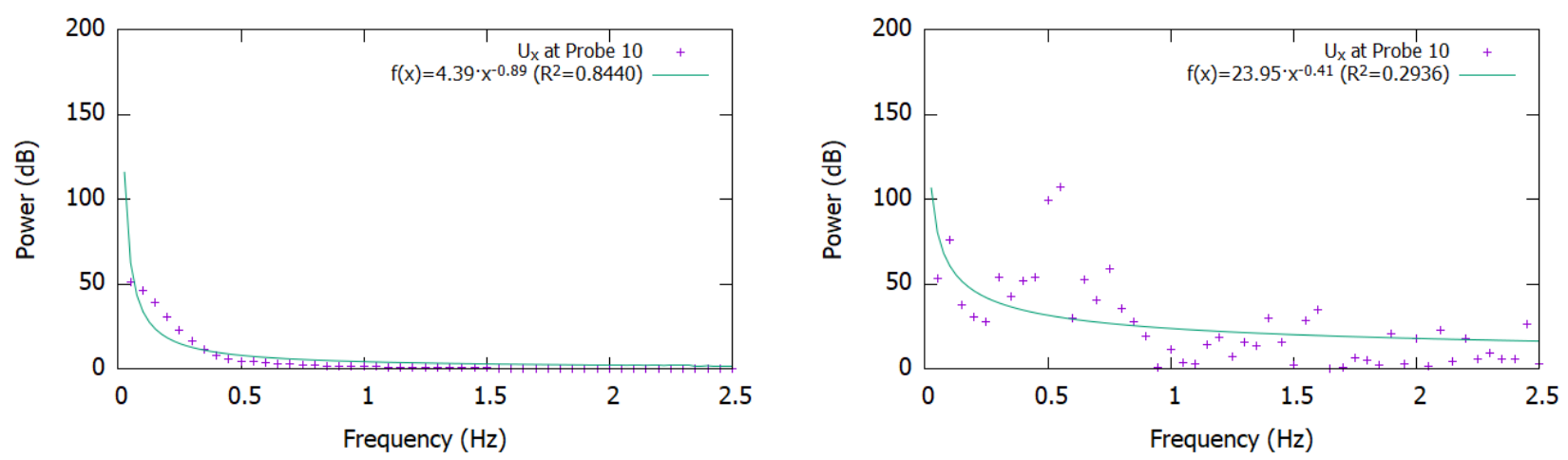

Figure 10. Power Spectral Density of $\Pi$ with Fitting Curve $(5 \mathrm{~m} / \mathrm{s})$
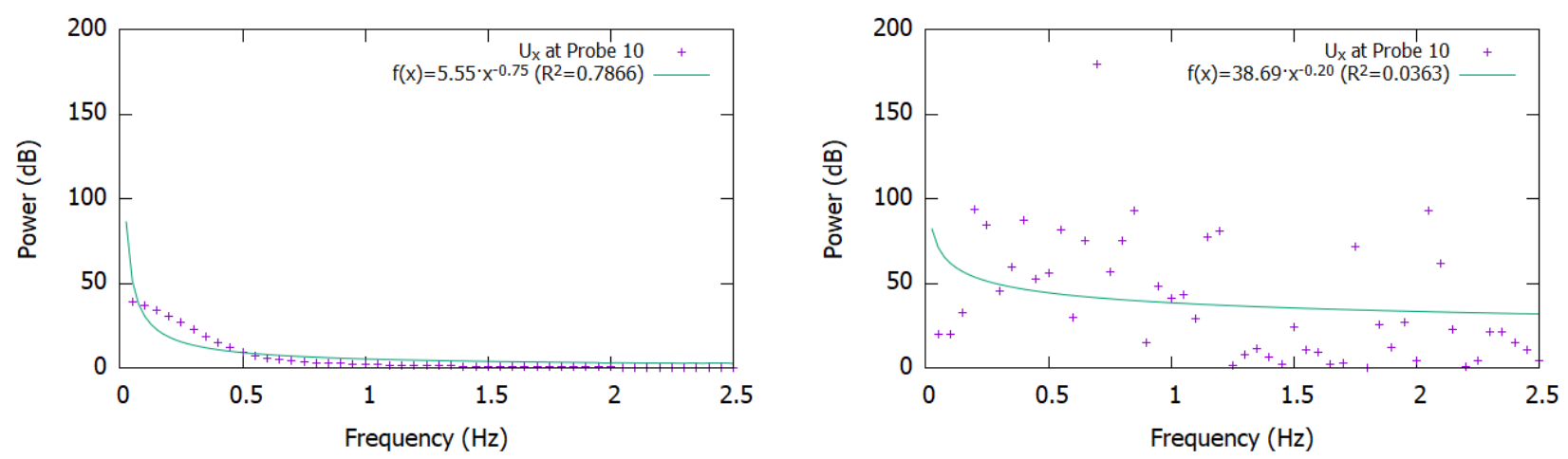


\section{CONCLUSION}

We have modeled a scenario of oil derivatives theft composed by a pipeline with a drilled outlet looking for a new approach to detect and track such leaks. We calculated power spectral density on the velocity fluctuations along the flow, by using the Fourier Transform. We also modeled a control scenario with a pipeline in prestige condition to compare results.

By probing velocity fluctuations along the pipeline flow and using Fourier Transform, we found that frequencies in pristine ducts had power decay in a wellformed curve. By using regression, we found Power Laws that rule those curves with high correlations.

We also found that for the condition proposed, predominant frequencies are low frequencies, below $1 \mathrm{~Hz}$, independently of the proximity of the probe to the leak and of the velocity of the flow, uncovering the presence of the leak nearby, the sources of vorticity injection. This means that, if the spectra can be measured along the duct near the wall, a change in the lower range of the spectra can be used as a diagnosis for the proximity of a theft. In higher frequencies (with less power) range, at least for a lower Reynolds number, the spectra were independent from the distance to the leak.

\section{REFERENCES}

1 MURVAY, P; and SILEA, I. A survey on gas leak detection and localization techniques. Journal of Loss Prevention in the Process Industries, 25(6):966 - 973, 2012.

2 Billmann, L. and Isermann, R. Leak detection methods for pipelines. Automatica, 23(3):381 - 385, 1987.

${ }^{3}$ Moisés dos Santos/Vanguarda Repórter. An oil derivative theft scenario in brazil.

https://g1.globo.com/sp/vale-do-paraiba-regiao/noticia/combustivel-e-furtadode-duto-da-petrobras-em-cacapava-sp.ghtml, 2017.

4 The OpenFOAM Foundation. OpenFOAM v7 User Guide.

https://cfd.direct/openfoam/user-guide.

${ }^{5}$ Osborne Reynolds. XXIX. An experimental investigation of the circumstances which determine whether the motion of water shall be direct or sinuous, and of the law of resistance in parallel channels. Philosophical Transactions of the Royal Society of London. 174:935-982. 1883.

${ }^{6}$ Joseph Smagorinsky. General circulation experiments with the primitive equations.

Monthly Weather Review, 91(3):99\{164, 1963.

7 Massimo Germano, Ugo Piomelli, Parviz Moin, and William H. Cabot. A dynamic subgrid-scale eddy viscosity model. Physics of Fluids A: Fluid Dynamics, 3(7):17601765, 1991. 